\title{
18
}

\section{Neurological Factors in Cognitive Aging}

\author{
RoBert S. WILSON
}

I

$\mathrm{n}$ the past century, average life expectancy in the United States increased by approximately 30 years, primarily because of reduced mortality from common conditions in early and midlife. As a result, there has been a substantial increase in the proportion of older people in the population, and this proportion is expected to further increase in the first half of the current century as the post-World War II generation ages. With the aging of the population, common chronic conditions of old age have come to pose an increasing public health burden. In particular, cognition-impairing conditions such as Alzheimer's disease that are relatively uncommon before age 65 have now become leading causes of morbidity and mortality. Therefore, identifying factors that may prevent or delay age-related cognitive decline is of great public health importance.

The central premise of this chapter is that age-related cognitive decline represents the interaction of experiential and genetic risk factors with multiple age-associated neuropathologic processes taking place in brains with differing structural and functional characteristics prior to old age. According to this view, age-related loss of cognition is not a normal developmental process or an inevitable outcome of old age but rather the result of different age-related neuropathologic lesions accumulating at different rates in different brain regions of individuals with differing vulnerabilities to the lesions; that is, risk factors may contribute to loss of cognition either by affecting the accumulation of common neuropathologic lesions or by somehow affecting the ability to maintain function despite accumulating pathology. To the extent that this view is valid, understanding the neurobiologic pathways linking risk factors to age-related loss of cognition is likely to be critical to research on prevention.

The remainder of this chapter is divided into three parts. In the first section, I describe four neuropathologic lesions that are common findings on postmortem examinations of the brains of old people and discuss their distribution and relation to cognition in people with and without dementia. In the second section, I consider selected predictors of age-related cognitive decline and propose different neurobiologic bases for the associations. In the final section, 
I summarize the preceding sections and consider implications for future research.

\section{Age-Related Neuropathology}

Alzheimer's disease is the most common cause of cognitive decline and dementia in old age. It has two defining pathologic features, first described by Alzheimer about 100 years ago: neuritic plaques, which accumulate outside neurons and mainly consist of a protein called amyloid-beta, and neurofibrillary tangles, which are found inside neurons, primarily consist of a protein called tau and appear as a tangled mass of filaments under a microscope. Both of these lesions are commonly found on postmortem examination of the brains of people who died in old age. The pathologic diagnosis of Alzheimer's disease is determined by the severity of this pathology, with the Consortium to Establish a Registry for Alzheimer's Disease criteria based on estimates of neuritic plaque density (Mirra et al., 1991), the Braak staging system based on neurofibrillary pathology (Braak \& Braak, 1991), and the National Institute on Aging research criteria based on both plaques and tangles ("Consensus recommendations," 1997).

Plaques and tangles are not the only forms of pathology contributing to late life cognitive impairment. Cerebral infarction is common. Thus, in the Religious Orders Study (Wilson, Bienias, Evans, \& Bennett, 2004), a longitudinal clinical-pathologic study of Catholic clergy members with a mean age at death of about 85 , more than one third had one or more chronic cerebral infarctions on brain autopsy (Schneider, Wilson, Bienias, Evans, \& Bennett, 2004; Schneider et al., 2003). Both infarction and Alzheimer's disease pathology were negatively associated with level of cognitive function proximate to death, and these associations were independent, meaning the negative effects were additive. In a subsequent study of this same cohort, Lewy bodies were present in about 15\% and associated with cognitive impairment, and only 2 brains out of more than 200 autopsies showed no evidence of Alzheimer's disease, cerebral infarction, or Lewy bodies (Wilson, Arnold, Schneider, Li, \& Bennett, 2007).
Although these neuropathologic lesions are common in old age and known to be correlated with age-related cognitive impairment, the correlation is far from perfect; that is, some people show little or no cognitive impairment despite substantial pathology while others have profound cognitive impairment despite minimal pathology. In the Religious Orders Study, for example, measures of amyloid, tangles, Lewy bodies, and cerebral infarction together accounted for $26.9 \%$ of the variance in a measure of global cognition proximate to death, after accounting for the effects of age at death, sex, and education (Wilson, Arnold, et al., 2007). That a substantial proportion of the variance in late life cognitive function is not associated with the leading causes of late life dementia suggests that other factors are involved, either other lesions whose pathologic footprint we do not yet recognize or structural or functional properties of neural systems that render them more or less able to effectively adapt to changes caused by age-related pathology.

A common idea in aging research is that normal aging can and should be distinguished from abnormal aging. This idea assumes that the factors contributing to late life dementia are different from the factors contributing to subtle changes in memory and cognition seen in old people without dementia. Recent clinicalpathologic research suggests that this assumption is incorrect. A substantial number of older persons exhibit some cognitive dysfunction but do not meet criteria for dementia, and the term mild cognitive impairment is increasingly being used to designate this border zone between normal cognition and dementia. In persons with mild cognitive impairment proximate to death, levels of Alzheimer's disease pathology (Bennett, Schneider, Wilson, et al., 2005; Petersen et al., 2006) and cerebral infarction (Bennett, Schneider, Wilson, et al., 2005) have been shown to be intermediate between levels in persons with no cognitive impairment and those with dementia. Neurofibrillary pathology in particular has been proposed as the pathologic substrate of mild cognitive impairment (Guillozet, Weintraub, Mash, \& Mesulam, 2003; Riley, Snowden, \& Markesbery, 2002) and, from a neuropathologic standpoint, mild cognitive impairment has been characterized as early 


\section{0 • BIOLOGICAL INDICATORS AND HEALTH-RELATED PROCESSES}

Alzheimer's disease (Markesbery et al., 2006). Neither is the impact of age-related neuropathology confined to persons with mild cognitive impairment. In one clinical-pathologic study with detailed annual cognitive testing and clinical evaluation, all those with mild cognitive impairment or dementia were excluded, leaving 134 persons who died without any evidence of cognitive impairment proximate to death (Bennett, Schneider, Arvanitakis, et al., 2006). More than one third met pathologic criteria for Alzheimer's disease (and more than one fifth had cerebral infarctions, and more than one eighth had Lewy bodies), and meeting Alzheimer's disease criteria was associated with lower episodic memory performance. Indeed, the correlation of Alzheimer's disease pathology with cognition does not appear to vary across the spectrum from dementia to mild cognitive impairment to no cognitive impairment (Bennett, Schneider, Wilson, et al., 2005).

If most old people have at least some Alzheimer's disease pathology and it negatively affects cognitive functioning across the full spectrum of cognitive ability, we may ask when these deleterious effects begin. Dementia due to Alzheimer's disease is strongly age related (Evans et al., 2003; Evans et al., 1989; Zhang et al., 1990), and the diagnosis is relatively uncommon in those aged less than 65. Yet the onset of dementia in Alzheimer's disease is difficult to pinpoint, and it is typically preceded by years of subtle impairments in cognition and other neurobehavioral functions. Studies of persons who eventually developed Alzheimer's disease suggest a prodromal period of several years duration marked by cognitive decline and atrophic changes in the medial temporal lobe (Twamley, Ropacki, \& Bondi, 2006). Neuropathologic research also suggests that the medial temporal lobe is among the first sites of Alzheimer's disease pathologic changes (Braak \& Braak, 1991; Hyman, Van Hoesen, Kromer, \& Damasio, 1984). In the Braak model of the natural history of Alzheimer's disease, neurofibrillary pathology is confined to transentorhinal and entorhinal cortices during a long clinically silent phase of the disease followed by a spread of pathology to other limbic structures and the appearance of prodromal clinical symptoms during a subsequent limbic phase (Braak \& Braak,
1991). A remarkable feature of the autopsy series of Braak and Braak (1991), based on 2,661 brains obtained from three German universities, is that neurofibrillary pathology was relatively common prior to old age, with one third of those under the age of 50 showing at least some tangles in the entorhinal cortex (though only 6\% showed evidence of amyloid-beta accumulation at this age). Further evidence that Alzheimer's disease may begin in middle age comes from studies of persons genetically at risk for the disease. Thus, healthy persons in their 50s with two copies of the apolipoprotein $\mathrm{E} \varepsilon 4$ allele have been shown to exhibit subtle deficits in visual attention and working memory (Greenwood, Lambert, Sunderland, \& Parasuraman, 2005) which progressively worsen (Greenwood, Sunderland, Putnam, Levy, \& Parasuraman, 2005).

\section{PREDictors OF \\ Age-Related Loss of Cognition}

In the past decade, a wide array of genetic, clinical, and lifestyle variables has been associated with cognitive decline and dementia in prospective observational studies. Developing effective strategies to prevent or delay age-related cognitive decline is likely to depend in part on understanding the neurobiologic mechanisms linking these variables to late life cognitive function. As shown in the preceding section of this chapter, the long prodromal period in Alzheimer's disease and individual differences in the ability to tolerate its pathology complicate efforts to identify these mechanisms. In this section, I consider four possible mechanisms and provide examples of each.

\section{Early Signs of Neuropathology}

Given the long prodromal period in Alzheimer's disease, it is likely that some variables that predict cognitive decline are not true risk factors but subtle early signs of its pathology. Thus, difficulty identifying familiar odors is associated with more rapid cognitive decline (Graves et al., 1999; Wilson, Arnold, Tang, \& Bennett, 2006) and with the transitions from no cognitive impairment to mild cognitive impairment (Wilson, Schneider, Arnold, et al., 2007) and from mild cognitive impairment to Alzheimer's disease (Devanand 
et al., 2000; Tabert et al., 2005; Wilson, Schneider, Arnold, et al., 2007). These correlations are likely due in large part to a robust association of olfactory identification with neurofibrillary pathology in the entorhinal cortex, hippocampus, and other central olfactory regions (Wilson, Arnold, Schneider, Tang, \& Bennett, 2007). Similarly, Parkinsonian gait dysfunction has been associated with risk of dementia (Louis, Tang, \& Mayeux, 2004; Wilson, Schneider, Bienias, Evans, \& Bennett, 2003) and with neurofibrillary pathology in the substantia nigra (Schneider et al., 2006), and loss of body mass is associated with cognitive decline (Buchman et al., 2005) and Alzheimer's disease pathology (Buchman, Schneider, Wilson, Bienias, \& Bennett, 2006).

\section{Factors Associated With Accumulation of Neuropathology}

Given the prevalance in old age of neuropathologic lesions associated with cognitive impairment, it is not surprising that some factors appear to predict age-related cognitive decline by virtue of an association with neuropathology. Thus, possession of at least one copy of the apolipoprotein E $\varepsilon 4$ allele, a well-established risk factor for cognitive decline and Alzheimer's disease (Corder et al., 1993; Evans et al., 2003), has been associated with amyloid deposition in the brain (Polvikoski et al., 1995; Schmechel et al., 1993). In clinical-pathologic analyses in the Religious Orders Study (Bennett, Schneider, Wilson, et al., 2005), possession of an $\varepsilon 4$ allele was associated with lower level of cognitive function proximate to death. After controlling for a composite measure of amyloid burden based on tissue from eight brain regions, this association was reduced by about $60 \%$ and was no longer significant. The $\varepsilon 4$ allele was also related to a measure of tangle density, but the association was eliminated after controlling for amyloid load. The $\varepsilon 4$ allele has also been associated with increased likelihood of cerebral infarction (Schneider et al., 2005). These data suggest that the association of $\varepsilon 4$ with cognitive impairment is largely mediated by its association with neuropathologic lesions known to contribute to cognitive impairment in old age.

Diabetes mellitus affects about one fifth of persons aged 65 years or older in the United
States (National Institute of Diabetes and Digestive and Kidney Diseases, 2002). Large prospective studies have found persons with diabetes to experience more rapid cognitive decline (Arvanitakis, Wilson, Bienias, Evans, \& Bennett, 2004; Kanaya, Barrett-Conner, Gildengorin, \& Yaffe, 2004; Logroscino, Kang, \& Grodstein, 2004) and an increased risk of dementia (Arvanitakis et al., 2004; Leibson et al., 1997; Ott et al., 1999) compared to persons without diabetes. In clinical-pathologic analyses from the Religious Orders Study (Arvanitakis et al., 2006), diabetes was associated with the presence of cerebral infarction on postmortem examination but not with composite measures of amyloid load or tangle density, suggesting that diabetes is associated with age-related cognitive decline by virtue of an association with cerebral infarction.

\section{Factors Modifying the Association of Neuropathology With Cognition}

Several large epidemiologic studies have found that people with higher levels of educational or occupational attainment have a decreased risk of late life dementia compared to persons with lower levels of attainment (Evans et al., 1997; Stern et al., 1994; Wilson, Bennett, et al., 2002). Because few investigators believed that education or occupation were associated with the pathology underlying dementia, the observation suggested that education might be a marker of brain's ability to tolerate age-related neuropathology. Support for this idea comes from analyses of clinical and pathologic data from the Religious Orders Study (Bennett et al., 2003). Among those who died and underwent brain autopsy, the negative association of Alzheimer's disease pathology with cognitive function proximate to death was reduced in participants with higher levels of schooling compared to those with lower levels; that is, it took about 5 times more pathology to reduce cognition by a fixed amount in a person with a high level of education relative to a person with a low level, consistent with the neural reserve hypothesis.

Having a large social network has been associated with reduced risk of cognitive decline and dementia (L. L. Barnes, Mendes de Leon, Wilson, Bienias, \& Evans, 2004; Fratiglioni, Wang, Ericsson, Maytan, \& Winblad, 2000; 


\section{2 • BIOLOGICAL INDICATORS AND HEALTH-RELATED PROCESSES}

Zunzunegui, Alvarado, Del Ser, \& Otero, 2003), although negative results have also been reported (Wilson, Krueger, et al., 2007). In a recent clinical-pathologic study, social network size modified the association of neurofibrillary pathology with cognitive function proximate to death (Bennett, Schneider, Tang, et al., 2006). As social network size increased, the negative correlation of tangles with cognition decreased, suggesting that neural systems involved in developing and maintaining a large social network may help the brain function despite increasing neurofibrillary changes, possibly by facilitating recruitment of additional neural systems during cognitive processing.

\section{Factors Operating Through Other Mechanisms}

For many factors that have been found to predict age-related loss of cognition, the neurobiologic basis of the association is uncertain, and in some cases novel mechanisms have been hypothesized. A case in point is depressive symptomatology. With relatively few exceptions, longitudinal studies have found higher level of depressive symptoms in old age to be associated with loss of cognition in the form of higher incidence of mild cognitive impairment (D. E. Barnes, Alexopoulos, Lopez, Williamson, \& Yaffe, 2006: Geda et al., 2006; Wilson, Schneider, Boyle, et al., 2007) or dementia (Berger, Fratiglioni, Forsell, Winblad, \& Bäckman, 1999; Devanand et al., 1996; Gatz, Tyas, St. John, \& Montgomery, 2005; Modrego \& Ferrández, 2004; Wilson, Barnes, et al., 2002; Wilson, Krueger, et al., 2007) or more rapid cognitive decline (Paterniti, Verdier-Tillefer, Dufouil, \& Alperovitch, 2002; Sachs-Ericsson, Joiner, Plant, \& Blazer, 2005; Wilson, Barnes, et al., 2002; Wilson, Mendes de Leon, Bennett, Bienias, \& Evans, 2004; Yaffe et al., 1999). One interpretation of these data is that depressive symptoms are an early sign of the pathology associated with dementia. Yet longitudinal studies do not suggest that depressive symptoms worsen in old age (Barefoot, Mortensen, Helms, Avlund, \& Schroll, 2001; Davey, Halverson, Zonderman, \& Costa, 2004; Haynie, Berg, Johansson, Gatz, \& Zarit, 2001; Pitkälä, KähönenVäre, Valvanne, Strandberg, \& Tilvis, 2003;
Skarupski et al., 2005; Wallace \& O'Hara, 1992) when neuropathology is accumulating in the brain, unlike other established signs that predict cognitive decline (i.e., olfactory identification, body mass, gait). Furthermore, in the Religious Orders Study, the level of depressive symptoms was not related to cerebral infarction or composite measures of amyloid load, tangle density, or Lewy bodies and did not modify the relation of pathology to cognition. However, depressive symptomatology was related to likelihood of dementia and level of cognitive function proximate to death, even after controlling for all forms of neuropathology (Wilson, Arnold, et al., 2007). These data suggest that the association of depressive symptoms with agerelated loss of cognition may be independent of the neuropathology traditionally associated with dementia and that novel pathologic changes may be involved. Animal models of chronic stress have described a spectrum of limbic system changes, particularly in portions of the hippocampal formation and medial prefrontal cortex, including dendritic atrophy, downregulation of glucocorticoid receptors, and reduced expression of brain-derived neurotrophic factor and its tyrosine kinase $\mathrm{B}$ receptor, accompanied by impaired learning and memory (Johren, Flugge, \& Fuchs, 1994; Magarinos, McEwan, Flugge, \& Fuchs, 1996; Radley et al., 2004; Smith Makino, Kvetnansky, \& Post, 1995; Sousa, Lukoyanov, Madeira, Almeida, \& PaulaBarbosa, 2000). That these models might have relevance to humans is suggested by neuroimaging evidence of reduced volume of the hippocampus and prefrontal cortex in major depression (Drevets et al., 1997; Sheline, Wang, Gado, Csernansky, \& Vannier, 1996) and postmortem evidence of reduced glucocorticoid receptor mRNA in the hippocampus and frontal cortex in persons with mood disorders (Webster, Knable, O'Grady, Orthman, \& Weickert, 2002) and reduced expression of brain-derived neurotrophic factor in suicide victims (Dwivedi et al., 2003).

\section{CONCLUSION}

In this chapter, I have discussed the neuropathologic lesions associated with Alzheimer's 
disease, stroke, and Parkinson's disease, common age-related conditions that impair cognitive function. I have tried to make two main points. First, these lesions, particularly Alzheimer's disease pathology, are commonly found in the brains of older people without dementia and are known to adversely affect cognition in this subgroup, suggesting that the distinction between normal and abnormal cognitive aging is artificial and constrains thinking about the bases of agerelated loss of cognition. Second, these common neuropathologies do not account for all of the heterogeneity in age-related loss of cognition, implying that other neurobiologic mechanisms are involved, possibly by somehow modifying the association of pathology with cognition or by an association with currently unrecognized neurodeteriorative changes.

Future research on age-related loss of cognition faces many challenges, two in particular. First, knowledge of the natural history of Alzheimer's disease is sketchy, but current data suggest that the initial pathological changes in the brain may precede the first clinical manifestations of the disease by many years. Better understanding of this long period may help to inform strategies for delaying symptom onset and for identifying people with the disease before debilitating pathologic and cognitive changes have taken place. A second challenge is to clarify the structural, biochemical, and molecular bases of individual differences in vulnerability to age-related pathology, which may suggest novel preventive strategies.

\section{REFERENCES}

Arvanitakis, Z., Schneider, J. A., Wilson, R. S., Li, Y., Arnold, S. E., Wang, Z., et al. (2006). Diabetes is related to cerebral infarction but not to $\mathrm{AD}$ pathology in older persons. Neurology, 67, 1960-1965.

Arvanitakis, Z., Wilson, R. S., Bienias, J. L., Evans, D. A., \& Bennett, D. A. (2004). Diabetes mellitus and risk of Alzheimer's disease and decline in cognitive function. Archives of Neurology, 61, 661-666.

Barefoot, J. C., Mortensen, E. L., Helms, M. J., Avlund, K., \& Schroll, M. (2001). A longitudinal study of gender differences in depressive symptoms from age 50 to 80 . Psychology and Aging, 16, 342-345.
Barnes, D. E., Alexopoulos, G. S., Lopez, O. L., Williamson, J. D., \& Yaffe, K. (2006). Depressive symptoms, vascular disease, and mild cognitive impairment. Archives of General Psychiatry, 63, 273-280.

Barnes, L. L., Mendes de Leon, C. F., Wilson, R. S., Bienias, J. L., \& Evans, D. A. (2004). Social resources and cognitive decline in a population of older African Americans and whites. Neurology, 63, 2322-2326.

Bennett, D. A., Schneider, J. A., Arvanitakis, Z., Kelly, J. F., Aggarwal, N. T., Shah, R. C., et al. (2006). Neuropathology of older persons without cognitive impairment from two community-based studies. Neurology, 66, 1837-1844.

Bennett, D. A., Schneider, J. A., Tang, Y., Arnold, S. E., \& Wilson, R. S. (2006). The effect of social networks on the relation between Alzheimer's disease pathology and level of cognitive function in old people: A longitudinal cohort study. Lancet Neurology, 5, 406-412.

Bennett, D. A., Schneider, J. A., Wilson, R. S., Bienias, J. L., Berry-Kravis, E., \& Arnold, S. E. (2005). Amyloid mediates the association of apolipoprotein E $\varepsilon 4$ allele to cognitive function in older people. Journal of Neurology, Neurosurgery, and Psychiatry, 76, 1194-1199.

Bennett, D. A., Wilson, R. S., Schneider, J. A., Evans, D. A., Mendes de Leon, C. F., Arnold, S. E., et al. (2003). Education modifies the relation of $\mathrm{AD}$ pathology to level of cognitive function in older persons. Neurology, 60, 1909-1915.

Berger, A. K., Fratiglioni, L., Forsell, Y., Winblad, B., \& Bäckman, L. (1999). The occurrence of depressive symptoms in the preclinical phase of AD: A population-based study. Neurology, 53, 1998-2002.

Braak, H., \& Braak, E. (1991). Neuropathological staging of Alzheimer-related changes. Acta Neuropathologica, 82, 239-259.

Buchman, A. S., Schneider, J. A., Wilson, R. S., Bienias, J. L., \& Bennett, D. A. (2006). Body mass index in older persons is associated with Alzheimer's disease pathology. Neurology, 67, 1949-1954.

Buchman, A. S., Wilson, R. S., Bienias, J. L., Shah, R. C., Evans, D. A., \& Bennett, D. A. (2005). Change in body mass index (BMI) and risk of incident Alzheimer's disease. Neurology, 65, 892-897.

Consensus recommendations for the postmortem diagnosis of Alzheimer's disease. The National Institute on Aging, and Reagen Institute 


\section{4 • BIOLOGICAL INDICATORS AND HEALTH-RELATED PROCESSES}

Working Group on Diagnostic Criteria for the Neuropathological Assessment of Alzheimer's Disease. (1997). Neurobiology of Aging, 18(4, Suppl.), S1-S2.

Corder, E. H., Saunders, A. M., Strittmatter, W. J., Schmechel, D. E., Gaskell, P. C., Small, G. W., et al. (1993, August 13). Gene dose of apolipoprotein E type 4 allele and the risk of Alzheimer's disease in late onset families. Science, 261, 921-923.

Davey, A., Halverson, C. F., Zonderman, A. B., \& Costa, P. T. (2004). Change in depressive symptoms in the Baltimore Longitudinal Study of Aging. Journal of Gerontology: Psychological Sciences, 59B, P270-P277.

Devanand, D. P., Michaels-Marston, K. S., Liu, X., Pelton, G. H., Padilla, M., Marder, K., et al. (2000). Olfactory deficits in patients with mild cognitive impairment predict Alzheimer's disease at follow-up. American Journal of Psychiatry, 157, 1399-1405.

Devanand, D. P., Sano, M., Tang, M. X., Taylor, S., Gurland, B. J., Wilder, D., et al. (1996). Depressed mood and the incidence of Alzheimer's disease in the elderly living in the community. Archives of General Psychiatry, 53, 175-182.

Drevets, W. C., Price, J. L., Simpson, J. R., Todd, R. D., Reich, T., Vannier, M., et al. (1997, April 24). Subgenual prefrontal cortex abnormalitites in mood disorders. Nature, 386, 824-827.

Dwivedi, Y., Rizavi, H. S., Conley, R. R., Roberts, R. C., Tamminga, C. A., \& Pandey, G. N. (2003). Altered gene expression of brain-derived neurotrophic factor and receptor tyrosine kinase B in post-mortem brain of suicide subjects. Archives of General Psychiatry, 60, 804-815.

Evans, D. A., Bennett, D. A., Wilson, R. S., Bienias, J. L., Morris, M. C., Scherr, P. A., et al. (2003). Incidence of Alzheimer's disease in a biracial urban community: Relation to apolipoprotein E allele status. Archives of Neurology, 60, 185-189.

Evans, D. A., Funkenstein, H. H., Albert, M. S., Scherr, P. A., Cook, N. R., Chown, M. J., et al. (1989). Prevalance of Alzheimer's disease in a community population of older persons. Higher than previously reported. Journal of the American Medical Association, 262, 2551-2556.

Evans, D. A., Hebert, L. E., Beckett, L. A., Scherr, P. A., Albert, M. S., Chown, M. J., et al. (1997). Education and other measures of socioeconomic status and risk of incident Alzheimer's disease in a defined population of older persons. Archives of Neurology, 54, 1399-1405.

Fratiglioni, L., Wang, H. X., Ericsson, K., Maytan, M., \& Winblad, B. (2000). Influence of social network on occurrence of dementia: A communitybased longitudinal study. The Lancet, 355, 1315-1319.

Gatz, J. L., Tyas, S. L., St. John, P., \& Montgomery, P. (2005). Do depressive symptoms predict Alzheimer's disease and dementia? Journal of Gerontology: Medical Sciences, 60A, 744-747.

Geda, Y. E., Knopman, D. S., Mrazek, D. A., Jicha, G. A., Smith, X. X., Negash, S., et al. (2006). Depression, apolipoprotein E genotype, and the incidence of mild cognitive impairment. Archives of Neurology, 63, 435-440.

Graves, A. B., Bowen, J. D., Rajaram, L., McCormick, W. C., McCurry, S. M., Schellenberg, G. D., et al. (1999). Impaired olfaction as a marker for cognitive decline: Interaction with apolipoprotein E $\varepsilon 4$ status. Neurology, 53, 1480-1487.

Greenwood, P. M., Lambert, C., Sunderland, T., \& Parasuraman, R. (2005). Effects of apolipoprotein E genotype on spatial attention, working memory, and their interaction in healthy, middle-aged adults: Results from the National Institute of Mental Health's BIOCARD study. Neuropsychology, 19, 199-211.

Greenwood, P. M., Sunderland, T., Putnam, K., Levy, J., \& Parasuraman, R. (2005). Scaling of visuospatial attention undergoes differential longitudinal change as a function of APOE genotype prior to old age: Results from the NIMH BIOCARD study. Neuropsychology, 19, 830-840.

Guillozet, A. L., Weintraub, S., Mash, D. C., \& Mesulam, M. M. (2003). Neurofibrillary tangles, amyloid, and memory in aging and mild cognitive impairment. Archives of Neurology, 60, 729-736.

Haynie, D. A., Berg, S., Johansson, B., Gatz, M., \& Zarit, S. H. (2001). Symptoms of depression in the oldest old: A longitudinal study. Journal of Gerontology: Psychological Sciences, 56B, P111-P118.

Hyman, B. T., Van Hoesen, G. W., Kromer, C., \& Damasio, A. (1984, September 14). Alzheimer's disease: Cell specific pathology isolates the hippocampal formation. Science, 225, 1168-1170.

Johren, O., Flugge, G., \& Fuchs, E. (1994). Hippocampal glucocorticoid receptor expression 
in the tree shrew: Regulation by psychosocial conflict. Cellular and Molecular Neurobiology, 14, 281-296.

Kanaya, A. M., Barrett-Conner, E., Gildengorin, G., \& Yaffe, K. (2004). Change in cognitive function by glucose tolerance status in older adults: A 4-year prospective study of the Rancho Bernardo study cohort. Archives of Internal Medicine, 184, 1327-1333.

Leibson, C. L., Rocca, W. A., Hanson, V. A., Cha, R., Kokmen, E., O’Brien, P. C., et al. (1997). Risk of dementia among persons with diabetes mellitus: A population-based cohort study. American Journal of Epidemiology, 145, 301-308.

Logroscino, G., Kang, J. H., \& Grodstein, F. (2004). Prospective study of type 2 diabetes and cognitive decline in women aged 70-81 years. British Medical Journal, 328, 548-551.

Louis, E. D., Tang, M. X., \& Mayeux, R. (2004). Parkinsonian signs in older people in a community-based study: Risk of incident dementia. Archives of Neurology, 61, 1273-1276.

Magarinos, A. M., McEwan, B. S., Flugge, G., \& Fuchs, E. (1996). Chronic psychosocial stress causes apical dendrite atrophy of hippocampal CA3 pyramidal neurons in subordinate tree shrews. Journal of Neuroscience, 6, 3534-3540.

Markesbery, W. R., Schmitt, F. A., Kryscio, R. J., Davis, D. G., Smith, C. D., \& Wekstein, D. R. (2006). Neuropathologic substrate of mild cognitive impairment. Archives of Neurology, 63, 38-46.

Mirra, S. S., Heyman, A., McKeel, D., Sumi, S. M., Crain, B. J., Brownlee, L. M., et al. (1991). The Consortium to Establish a Registry for Alzheimer's Disease (CERAD). Part II: Standardization of the neuropathologic assessment of Alzheimer's disease. Neurology, 41, 479-486.

Modrego, P. J., \& Ferrández, J. (2004). Depression in patients with mild cognitive impairment increases the risk of developing dementia of Alzheimer type. Archives of Neurology, 61, 1290-1293.

National Institute of Diabetes and Digestive and Kidney Diseases. (2002). National diabetes statistics fact sheet: General information and national estimates on diabetes in the United States, 2000. Bethesda, MD: U.S. Department of Health and Human Services, National Institutes of Health.

Ott, A., Stolk, R. P., van Harskamp, F., Pols, H. A., Hofman, A., \& Breteler, M. M. (1999). Diabetes mellitus and the risk of dementia: The Rotterdam Study. Neurology, 53, 1937-1942.

Paterniti, S., Verdier-Taillefer, M.-H., Dufouil, C., \& Alperovitch, A. (2002). Depressive symptoms and cognitive decline in elderly people. British Journal of Psychiatry, 181, 404-410.

Petersen, R. C., Parisi, J. E., Dickson, D. W., Johnson, K. A., Knopman, D. S., Boeve, B. F., et al. (2006). Neuropathologic features of amnestic mild cognitive impairment. Archives of Neurology, 63, 665-672.

Pitkälä, K., Kähönen-Väre, M., Valvanne, J., Strandberg, R. S., \& Tilvis, R. S. (2003). Longterm changes in mood of an aged population: Repeated Zung-tests during a 10-year follow-up. Archives of Gerontology and Geriatrics, 36, 185-195.

Polvikoski, T., Sulkava, R., Haltia., M., Kainulainen, K., Vuorio, A., Verkkoniemi, A., et al. (1995). Apolipoprotein E, dementia, and cortical deposition of beta-amyloid protein. New England Journal of Medicine, 333, 1242-1247.

Radley, J. J., Sisti, H. M., Hao, J., Rocher, A. B., McCall, T., Hof, P. R., et al. (2004). Chronic behavioral stress induces apical dendritic reorganization in pyramidal neurons of the medial prefrontal cortex. Neuroscience, 125, 1-6.

Riley, K. P., Snowden, D. A., \& Markesbery, W. R. (2002). Alzheimer's neurofibrillary pathology and the spectrum of cognitive function: Findings from The Nun Study. Annals of Neurology, 51, 567-577.

Sachs-Ericsson, N., Joiner, T., Plant, E. A., \& Blazer, D. G. (2005). The influence of depression on cognitive decline in community-dwelling elderly persons. American Journal of Geriatric Psychiatry, 5, 402-408.

Schmechel, D. E., Saunders, A. M., Strittmatter, W. J., Crain, B. J, Hulette, C. M., Joo, S. H., et al. (1993). Increased amyloid beta-peptide deposition in cerebral cortex as a consequence of apolopoprotein E genotype in late-onset Alzheimer's disease. Proceedings of the National Academy of Sciences, USA, 90, 9649-9653.

Schneider, J. A., Bienias, J. L., Wilson, R. S., BerryKravis, E., Evans, D. A., \& Bennett, D. A. (2005). The apolipoprotein E $\varepsilon 4$ allele increases odds of chronic cerebral infarction detected at autopsy in older persons. Stroke, 36, 954-959.

Schneider, J. A., Li, J. L., Li, Y., Wilson, R. S., Kordower, J. H., \& Bennett, D. A. (2006). 


\section{6 - BIOLOGICAL INDICATORS AND HEALTH-RELATED PROCESSES}

Neurofibrillary tangles in the substantia nigra are related to gait impairment in older persons. Annals of Neurology, 59, 166-173.

Schneider, J. A., Wilson, R. S., Bienias, J. L., Evans, D. A., \& Bennett, D. A. (2004). Cerebral infarctions and the likelihood of dementia from Alzheimer's disease pathology. Neurology, 62, 1148-1155.

Schneider, J. A., Wilson, R. S., Bienias, J. L., Evans, D. A., Cochran, E. J., Arnold, S. E., et al. (2003). Relation of cerebral infarctions to dementia and cognitive function in older persons. Neurology, 60, 1082-1088.

Sheline, Y. I., Wang, P. W., Gado, M. H., Csernansky, J. G., \& Vannier, M. W. (1996). Hippocampal atrophy in recurrent major depression. Proceedings of the National Academy of Sciences, USA, 93, 3908-3913.

Skarupski, K., Mendes de Leon, C. F., Bienias, J. L., Barnes, L. L., Everson-Rose, S. A., Wilson, R. S., et al. (2005). Black-white differences in depressive symptoms among older adults over time. Journal of Gerontology: Psychological Sciences, 60B, P136-P142.

Smith, M. A., Makino, S., Kvetnansky, R., \& Post, M. (1995). Stress and glucocorticoids affect the expression of brain-derived neurotrophic factor and neurotrophin-3 mRNAs in the hippocampus. Journal of Neuroscience, 15, 1768-1777.

Sousa, N., Lukoyanov, N. V., Madeira, M. D., Almeida, O. F. X., \& Paula-Barbosa, M. M. (2000). Reorganization of the morphology of the hippocampal neurites and synapses after stressinduced damage correlates with behavioral improvements. Neuroscience, 97, 253-266.

Stern, Y., Gurland, B., Tatemichi, T., Tang, M. X., Wilder, D., \& Mayeux, R. (1994). Influence of education and occupation on the incidence of Alzheimer's disease. Journal of the American Medical Association, 271, 1004-1010.

Tabert, M. H., Liu, X., Doty, R. L., Serby, M., Zamora, D., Pelton, G. H., et al. (2005). A 10-item smell identification scale related to risk for Alzheimer's disease. Annals of Neurology, 58, 155-160.

Twamley, E. W., Ropacki, S. A. L., \& Bondi, M. W. (2006). Neuropsychological and neuroimaging changes in preclinical Alzheimer's disease. Journal of the International Neuropsychological Society, 12, 707-735.

Wallace, J., \& O’Hara, M. W. (1992). Increases in depressive symptomatology in the rural elderly:
Results from a cross-sectional and longitudinal study. Journal of Abnormal Psychology, 101, 398-404.

Webster, M. J., Knable, M. B., O’Grady, J., Orthman, J., \& Weickert, C. S. (2002). Regional specificity of brain glucocorticoid receptor mRNA alterations in subjects with schizophrenia and mood disorders. Molecular Psychiatry, 7, 985-994.

Wilson, R. S., Arnold, S. E., Schneider, J. A., Li, Y., \& Bennett, D. A. (2007). Chronic distress, agerelated neuropathology, and late life dementia. Psychosomatic Medicine, 69, 47-53.

Wilson, R. S., Arnold, S. E., Schneider, J. A., Tang, Y., \& Bennett, D. A. (2007). The relation of cerebral Alzheimer's disease pathology to odor identification in old age. Journal of Neurology, Neurosurgery, and Psychiatry, 78, 30-35.

Wilson, R. S., Arnold, S. E., Tang, Y., \& Bennett, D. A. (2006). Odor identification and decline in different cognitive domains in old age. Neuroepidemiology, 26, 61-67.

Wilson, R. S., Barnes, L. L., Mendes de Leon, C. F., Aggarwal, N. T., Schneider, J. A., Bach, J., et al. (2002). Depressive symptoms, cognitive decline, and risk of $\mathrm{AD}$ in older persons. Neurology, 59, 364-370.

Wilson, R. S., Bennett, D. A., Bienias, J. L., Aggarwal, N. T., Mendes de Leon, C. F., Morris, M. C., et al. (2002). Cognitive activity and incident $\mathrm{AD}$ in a population-based sample of older persons. Neurology, 59, 1910-1914.

Wilson, R. S., Bienias, J. L., Evans, D. A., \& Bennett, D. A. (2004). Religious Orders Study: Overview and change in cognitive and motor speed. Journal of Aging, Neuropsychology, and Cognition, 11, 281-303.

Wilson, R. S., Krueger, K. R., Arnold, S. E., Schneider, J. A., Kelly, J. F., Barnes, L. L., et al. (2007). Loneliness and risk of Alzheimer's disease. Archives of General Psychiatry, 64, 234-240.

Wilson, R. S., Mendes de Leon, C. F., Bennett, D. A., Bienias, J. L., \& Evans, D. A. (2004). Depressive symptoms and cognitive decline in a community population of older persons. Journal of Neurology, Neurosurgery, and Psychiatry, 75, 126-129.

Wilson, R. S., Schneider, J. A., Arnold, S. E., Tang, Y., Boyle, P. A., \& Bennett, D. A. (2007). Olfactory identification and incidence of mild cognitive impairment in old age. Archives of General Psychiatry, 64, 802-808. 
Wilson, R. S., Schneider, J. A., Bienias, J. L., Evans, D. A., \& Bennett, D. A. (2003). Parkinsonian-like signs and incident Alzheimer's disease in older persons. Archives of Neurology, 60, 539-544.

Wilson, R. S., Schneider, J. A., Boyle, P. A., Arnold, S. E., Tang, Y., \& Bennett, D. A. (2007). Chronic distress and incidence of mild cognitive impairment. Neurology, 68, 2085-2092.

Yaffe, K., Blackwell, T., Gore, R., Sands, L., Reus, V., \& Browner, W. S. (1999). Depressive symptoms and cognitive decline in nondemented elderly women. Archives of General Psychiatry, 56, 425-430.
Zhang, M. Y., Katzman, R., Salmon, D., Jin, H., Cai, G. J., Wang, Z. Y., et al. (1990). The prevalence of dementia and Alzheimer's disease in Shanghai, China: Impact of age, gender, and education. Annals of Neurology, 27, 428-437.

Zunzunegui, M. V., Alvarado, B. E., Del Ser, T., \& Otero, A. (2003). Social networks, social integration, and social engagement determine cognitive decline in community-dwelling Spanish older adults. Journal of Gerontology: Social Sciences, 58B, S93-S100. 